\title{
Assessment of Reservoir Storage in a Semi-Arid Environment Using Gould Probability Matrix
}

\author{
Ibn Abubakar, B.S.U
}

\begin{abstract}
This study made an assessment of the existing reservoir capacity of Tiga Dam in Kano State, Nigeria, of $1090 \times 10^{6} \mathrm{~m}^{3}$ using Gould Probability Matrix method. A generated annual inflow series between (1906 and 2004), rainfall and evaporation loss estimated for the period between 1990 and 2004 coupled with demand data obtained from Bichi (2003) and the Hadejia Jamaare River Basin Authority (HJRBA), are used in this study. The results indicated that the probability of failure approaches zero at a reservoir capacity of $540 x$ $10^{6} \mathrm{~m}^{3}$. Less than $0.25 \%$ probability of failure could be achieved with a capacity of $270 \times 10^{6} \mathrm{~m}^{3}$ and the downstream requirement could be increased to certain substantial amount by reducing the capacity of the dam thereby allowing flow into Hadejia-Jama'are River and Kumodugu-Yobe system which has been completely regulated. Increasing the downstream flow will alleviate social, economic and environmental trauma that had been subjected to the downstream community.
\end{abstract}

Key words Gould Probability Matrix; Tiga Dam; Probability of Failure; Reservoir Capacity; Downstream

\section{Introduction}

In developing countries, quite often in the semi-arid regions, developing and managing available surface water resources has been a crucial issue. These resources are an integral part of the natural environment. To determine effective societal water demands, e.g. for domestic, industrial, agricultural, hydropower generation and to protect human settlement from extreme floods, a system for water 
storage and distribution has been developed over the centuries to balance the uneven natural distribution of water.

In 1974, the then Kano State Government in North-Western Nigeria constructed a $6 \mathrm{~km}$ long high embankment dam-Tiga Dam across Kano River with original designed capacity of $1974 \times 10^{6} \mathrm{~m}^{3}$. It received as at the time of construction an average annual runoff $1.3 \times 10^{6} \mathrm{~m}^{3}$ and average annual rainfall of $1000 \mathrm{~mm}$ from a catchments area of 6553 $\mathrm{km}^{2}$. The main purpose was to provide substantial amount of water for Kano River Irrigation Project (stage I and II usually designated KRPI and KRPII), Kano city water supply, Hadejia valley irrigation project and a possible hydroelectric power generation (Haskoning Consultants, 1978).

It has resulted in posing more problems to the downstream beneficiaries than in harnessing surface water resources. For instance, the drainage patterns and hydrology of the Kano River had been changed downstream; storm channels narrowed while Kano River had become perennial in regime. Its discharge had been regulated. Ground water depleting on the Chad formation zone through rapid extraction from boreholes and recharge rate had been reduced due to impoundment upstream (Olofin, 1987). Already the argument for maintaining the natural river flows and flooding patterns may have been lost.

Many beneficiaries at the down stream site had been deprived and conflict between the requirements of Kano city and the major irrigation projects, and those of farmer, fishermen and wildlife in the Hadejia - Nguru wetland, had been reported in the literature (Carter, 1995). There was also no clear policy primarily based proper management of water demands for both downstream and upstream beneficiaries. Besides, lobby for fair deal by (downstream) Borno, Jigawa and Yobe states, were turned down (Carter, 1995). 
Moreover, the dam operation seemed evidently below utilisation capacity, as Kano City water supply expansion was still on course and the major irrigation projects such as Kano River Irrigation System phase I \& II and Hadejia valley irrigation project were still not completed. There was also clear indication of climatic change within the region as rainfall of North Central and North Eastern part of Nigeria had been on the decrease since 1961 to date (Gbuyiro, et al 2001). This paper sought to apply Gould probability procedure to assess the existing reservoir capacity of Tiga Dam and probability of failure in order to determine its ability to meet existing and planned demands and also to investigate the possibility of increasing the flow downstream.

\section{An Overview of Gould Probability Matrix Model}

In the past many studies had been reported in the development of models for determining reservoir storage for different conditions. Moran (1954) introduced a model that predicted the probability distribution of storage at the end of every successive year with an initial condition. He applied a Markov chains and multiplied with probability distribution of a discrete representation of storage by a transition matrix and thus obtained a probability distribution of a year ahead. Successive multiplications by the transition matrix will eventually converge to a steady state probability distribution that was independent of the initial condition and he assumed an independent annual flow. Gould (1961) modified the derivation of the transition matrix in the Moran model to include seasonal flow variations and intra-year autocorrelation using monthly rather than annual flows, and he included evaporation rates at the reservoir surface and withdrawal as a function of storage.

McMahon (1970) applied both Moran type models and Gould probability matrix to 156 Australian streams but modified the Gould Probability procedure and estimated the theoretical storage capacities for four draft conditions $(90 \%, 70 \%, 50 \%$ and 30\%) and three probability of failure values $(2.5 \% 5 \%$ and $10 \%)$. Park et al (1989) 
also applied the Gould method to catchments in Botswana for estimating the effect of rationing on the probability of failure of a reservoir.

Ragab, et al, (2001) also applied the modified Gould probability matrix to El-Gouazine catchments in Tunisia and obtained a probability of failure for different seasons both for summer and winter with their respective storage capacities. Raheem, et al (2002) has used the combination of probability of emptiness and mean first over flow time of a dam to determine its capacity. They used 34-years of historical inflow record of a Mitta Mitta river of Australia and applied the behavioural analysis to obtain the result.

\section{Study Area}

The area was underlain by rocks of the basement complex with intrusions of younger granite in the extreme southern parts. The Jurassic intrusion that affected the Jos Plateau occurred in this area and has been subjected to some form of weathering; their outcrop dominates the area such as in Riruwai. The highlands occupy a small area and consist mostly of younger granites, which rise more than $1100 \mathrm{~m}$ above mean sea level (Olofin, 1987).

The climate of the area was a semi-arid, tropical climate dominated by the tropical maritime air mass which brings rain from April to October and by the dry, dusty tropical continental air that prevailed from October to March (Woo Ming-ko, et al 1994). Mean annual rainfall was about $1000 \mathrm{~mm}$, decreasing to about $800 \mathrm{~mm}$ around Kano metropolitan. Great temporal variations occur in the amount of rainfall received anywhere in the area. Temperature regime was warm to hot throughout the year, even though there was a slightly cooler period between November and February. The mean annual temperature was about $26^{\circ} \mathrm{c}$ but mean monthly values range between $21^{\circ} \mathrm{c}$ in the coolest months (December - January) and $31^{\circ} \mathrm{c}$ in the hottest months (April/May). Variation in temperatures is very minimal. 


\section{Materials and Method Data Collection}

The application of the mass storage equation was data driven and the method for collecting the required data was through contact with the relevant authorities. Institutions such as Hadejia Jama'are River Basin Development Authority (HJRBDA), Aminu Kano International Airport, and the Institute for Agricultural Research (ABU) Kano Station were contacted and most of the data for this work was obtained from these sources.

There was no functional meteorological station currently at the dam site; therefore, the only available and consistently recorded meteorological data was that of Kano Airport and the Institute for Agricultural Research (ABU) Kano, both of which were situated about $100 \mathrm{~km}$ away from the reservoir. It was stated by Chow (1964) that it is not necessary that the rainfall station used for estimating peak flows be in the watershed under study. The only requirements were that the station used should experience the same precipitation frequency regime as the study basin and this may permit the use of data from as far as $160 \mathrm{~km}$. The monthly rainfall data was collected from IAR (ABU) Kano for periods between 1990 and 2004

Inflow data over the reservoir area was estimated using the rainfall data obtained from IAR Kano, converted into inflow using the reservoir area 72,000ha at full capacity. This inflow was added to the generated inflow which was obtained using the TAHAL consultant's theoretical inflow series updated to 2004. As stated earlier, the only available runoff records were those for the 1965 to 1971 at Tiga rapid hydrometric station that was discontinued. Therefore, for the purpose of this research, the estimated inflow series by the consultant was used. TAHAL consultant (1992) assumed that a satisfactory relationship between the Kano Airport rainfall records of (1905-1990) and measured inflow into Tiga reservoir of only 10 years (1965-1974) data available in the WRECA's hydrologic yearbook could be established; an 88 years design stream flow series had been generated. 
The consultant has also provided a table of theoretical average percentage distribution of monthly inflow series as shown below with respect to the generated inflow

The calculation of the theoretical monthly inflow series was completed using the percentage distribution given by TAHAL consultant to obtain the monthly inflow data for the analysis.

\section{Storage Capacity}

The estimate of storage capacity was based on the daily recorded reservoir level of Tiga between 1990 and 2004. In this study, due to the lack of functional hydro meteorological station at the site, the average monthly reservoir levels was used with reservoir area and capacity curves to obtain the average monthly reservoir storage. The average annual reservoir storage deduced from the reservoir area and capacity curves was used as the existing storage capacity and the average annual storage capacity as from 1990-2004 was obtained as $1090 \times 10^{6} \mathrm{~m}^{3}$.

\section{Water Demand}

\section{Domestic, Industrial and Irrigation Water Requirement}

The surface water requirement for both domestic and industrial supply was either directly abstracted from points well in riverbeds or to a lesser extent directly taken from the river. Estimation of domestic water requirement is largely determined by adequate population figures and level of urbanization. The National Population Commission had undertaken an estimation of the population of Kano state and its environs. Therefore, consultants such as Chifana (1984) and TAHAL (1994) had given the summary of the minimum and maximum estimated water demand which was given by the table 2 below.

It was estimated that about $203 \times 10^{6} \mathrm{~m}^{3}$ of water per year was required for the domestic use of Kano in the year 2001; out of which $103 \mathrm{x}$ $10^{6} \mathrm{~m}^{3}$ will be supplied from the dam while the remaining $100 \times 10^{6} \mathrm{~m}^{3}$ 
will be provided by Challawa Gorge reservoir. A recent study conducted by Bichi (2003) was used in the Greater Kano water supply project and estimated a requirement of $270 \times 10^{6} \mathrm{~m}^{3}$ in order to meet the demands of an increased population. . Tiga dam will therefore supply only $170 \times 10^{6} \mathrm{~m}^{3}$ and the remaining $100 \times 10^{6} \mathrm{~m}^{3}$ will come from the Challawa Gorge dam.

The irrigation water requirements for Kano river irrigation project were re-estimated by the consultants at $390 \times 10^{6} \mathrm{~m}^{3}$ for the gravity irrigation alternatives (TAHAL consultants annex 4). Therefore, an average inflow of $880 \times 10^{6} \mathrm{~m}^{3}$ had been assumed in addition to Kano City and KRPI requirements. A potential amount of $387 \times 10^{6} \mathrm{~m}^{3}$ could be supplied to downstream users. The distribution of average water demand on Tiga Dam is shown by figure 2 below.

There were generally two different ways of estimating evaporation, direct method using standard evaporation pan with effective pan coefficient and, by the use of empirical formulae. In this study therefore, evaporation was estimated based on the following general empirical formula (Wilson, 1990).

$$
E_{a}=0.35\left(E_{s}-E_{a}\right)(0.5+0.5 U) \quad 2.0
$$

Where $\mathrm{Ea}=$ open water evaporation in $\mathrm{mm} /$ day

Es = saturation vapour pressure of air at $\mathrm{t}^{\mathrm{o}} \mathrm{c}(\mathrm{mmHg})$

$\mathrm{Ea}=$ actual vapour pressure in the air $(\mathrm{mmHg})$

$\mathrm{U}=$ wind speed at same standard height $(\mathrm{m})$.

A psychometric table was used in obtaining saturated vapour pressures using the meteorological data obtained from the IAR (ABU) Kano.

\section{Model Procedure}

The generated data was applied to the following mass storage equation.

$$
V_{t+1}=V+\operatorname{Qin}_{t}-A b s_{t}-A e_{t}-D_{t}-S_{t}-\cdot-\cdot-\cdot-\cdot-\cdot-\cdot-\cdot-\cdot-\cdot--2.1
$$

Where; 
1. $\operatorname{Qin}_{(\mathrm{t})}$ : was the inflow in million cubic metres.

2. $\mathrm{Abs}_{(\mathrm{t})}$ : was the abstraction pattern if available.

3. $\operatorname{Ae}_{(\mathrm{t})}$ : was the evaporation.

4. $\mathrm{D}_{(\mathrm{t})}$ : were reservoir releases, both present and future.

5. V: was the reservoir volume.

6. $\mathrm{S}_{\mathrm{t}}$ : Siltation data if available.

\section{Construction of the Probability Matrix}

The detailed procedure to calculate systematically the probability of failure was summarised below (McMahon and Mein 1978).

(1) The input data in item (1-6 as mentioned above) was obtained form Hadejia Jamaare river basin authority.

(2) Tally sheets were set up and a transition matrix was constructed. This was done by dividing up the reservoir into ten equal zones (including exactly empty and exactly full).

(3) The continuity equation (eqn. 2.1) was applied on a monthly basis for reservoir balance, starting the reservoir in each of 9 zones and for each year of monthly data for a 15 year period (1990-2004) and tallied the number of times the reservoir "ends up" in each of the zones. Each column was divided by $\mathrm{N} \mathrm{x} \mathrm{K}$ where $\mathrm{N}$ is the years of data and $\mathrm{K}$ is the number of zones.

(4) For each of the starting zones, the number of times and months the reservoir fails counted. A total of $12 \mathrm{~N}$ months routed through each zone, the values converted to probability by dividing each entry by $12 \times \mathrm{N}$ (this step is different from the original Gould method where the failure was defined on an annual basis).

(5) A steady state of the matrix obtained, by powering up to 13 times using Matlab a mathematical software programme and solved the 9 × 9 matrix.

(6) The steady state probability of reservoir being in a particular zone (step 5) multiplied with the probability of failure for the zone (step 4). The result was the probability of failure of the reservoir. 


\section{Result, Discussion and Recommendation}

Figure 1 indicated that the demand on the reservoir was all year round; especially for Kano City water supply which was taken as constant demand at the time of this study. The rainfall figure was traditionally highest in the month of August which was generally common in the region and during that period the reservoir was receiving the highest inflow rate. The evaporation estimated also showed that the reservoir loses a lot of water throughout the year and with highest amount in the months of March and April.

The probability distribution for different starting and finishing conditions are shown in Table 1; zonal distributions of capacities are also indicated in Table 2. This figure also showed how the monthly probability of failure is obtained. The months of April and May have the highest values, while the rest of the months except from January December did not record any failure and that evaporation is low during that period while the reservoir receives highest inflow.

The "powering up" option was used and the 9x9 matrix was "powered up" up to 13 times to obtain the steady state solution given by the table 3 below.

Along side, a tally sheet for monthly failure was also observed and the following probability for monthly failure was obtained and is given in the table 4 below:

From Figure 1 it could be seen that the month of March showed about $0.25 \%$ probability, while April and May had equal value of about $0.345 \%$. This was only possible for starting capacities of between 0 and $480 \times 10^{6} \mathrm{~m}^{3}$.

Figure 3 also showed how the probability of failure decreased as the reservoir content increased. As stated earlier, the reservoir capacity was divided into ten zones. From Figure 3 the probability of zone 1 was very high and is about $0.425 \%$ and zone 4 is about $0.17 \%$ while from zone 5 upward no failure was recorded. Therefore, the 
probability of failure approaches zero as the reservoir content reaches zone 5. The probability of failure for the dam was obtained by the product of the two probabilities and was given in Table 4

Therefore, the probability of failure for the existing capacity with the current demand situation was $0.5 \%$ (99.5\% success).

\section{Conclusion}

The existing capacity of the dam had been successfully assessed on a monthly basis and a very high percentage of success had been obtained. Generally the probability failure approaches zero at a reservoir capacity of $548 \times 10^{6} \mathrm{~m}^{3}$. Above $0.25 \%$ probability of failure (99.75\% success) could be achieved with a reservoir capacity of $270 \times 10^{6} \mathrm{~m}^{3}$. This meant that the argument that substantial amount of water had been trapped without efficient utilisation is corroborated by this finding. However, since the climatic condition of the area was undergoing tremendous decrease in terms of amount of rainfall received, it was imperative that the capacity of the dam could be reduced. Consequently substantial volume of water could be allowed for the downstream users. This will go along way in alleviating the water requirement of downstream communities and thereby resuscitating many irrigation activities, fishing and also increase the flow into the Hadejia-Jama' are and Kumodugu Yobe systems. The benefit of increase to the downstream flow cannot be over emphasised, since the downstream communities have undergone and still experiencing social and economic trauma because of construction of this dam; argument for maintaining the natural river flows and flooding patterns could be brought back. Although, it may be argued that it was difficult to achieve considering the major river pattern in the Hadeja-Jama'are and Kumodugu-Yobe system have completely buried by siltation due to low flow ever since the construction of dam. However, the social, environmental and economic benefit of increasing the downstream flow could not be equated to what has been experienced by the community. Therefore, there was need to achieve 
the maximization of benefits deriving from available water resources and their most rational management

The application of this method was very effective as it had the advantage of sampling all years' data without reference to the sequence and is particularly suitable for catchments with patchy data. Nevertheless, it has to be borne in mind that the present analysis was based on the available estimated water demand and also on the assumption that the Kano Airport Meteorological data was similar to that of Tiga dam site additionally; there was no siltation rate data available

\section{Recommendation}

The following recommendations were suggested from the findings of the study:

(1) The owners of the dam should establish a functional hydro meteorological station for continuous recording of data for proper recording of data.

(2) The gauge station at Riruwai should be re-established in order to record inflow into the reservoir.

(3) The siltation rate data from the reservoir should be properly monitored and estimated as this generally contributes to the reduction of the reservoir capacity.

(4) The release to downstream users was very small and it is, therefore, necessary to increase the volume of release

(5) A further study should be carried out incorporating siltation rate, ground water abstraction data and on site evaporation data.

\section{Reference}

Bichi H. M. (2003) "Assessment of Water Demand Pattern in Sub-Saharan Africa a Case Study of the Greater Kano Area, Nigeria". Kano Studies New Series Vol. N0.2 pp 142-153

Carter, R.C. (1995) “A Policy Framework for Surface Water and Shallow Groundwater Allocation, With Special Refrence to the Komadongou Yobe River Basin", Northeast Nigeria. Public Administration and Development, Vol.15, pp 103-120 
Chifana Consultants (1984) "Improvement of River Channels along Hadejia between Geidam and Hadejia" Federal Ministry of Water Resources Abuja Nigeria.

Chow, V.T. (1964) Handbook of Applied Hydrology, New York; McGrawHill.

Gbuyiro, S. Ojo, O. Iso, M. Okoloye, C. and Idowu, O. (2001) "Climate and Water Resources Management" 27th WEDC Conference People and System for Water, Sanitation and Health, Lusaka, Zambia.

Gould, B. (1961) "Statistical Methods for Estimating the Design Capacity of Dams" Journal of the Institution for Engineers, Australia, 33(12), pp 405-415

Hadejia Jama'are River Basin Development Authority (1984). "Tiga Dam Assessment Reports" Kano, Nigeria.

McMahon, T.A. (1976) "Preliminary Estimation of Reservoir Storage for Australian Streams", Civil Engineering Transactions. The Institution of Engineers, Australia CE 18(2):55-59

McMahon, T.A. and Mein, R.G. (1978) Reservoir Capacity and Yield. The Netherlands: Elsevier Scientific Publishing Company.

Moran, P.A. (1954) "A Probability Theory of Dams and Storage Systems" Australian Journal of Applied Science, 5(2), 116-124

National Population Commission (1992) 1991 National Populations Series, Lagos: National Population Commission.

Olofin, E.O. (1987) "Some Aspect of the Physical Geography of Kano Region and Related Human Resources", Departmental Lecture, Department of Geography, Bayero University Kano.

Parks, N.P. Fargusharson, F.A.K. and Plinston, D.T.(1989) "Use of the Gould Probability Matrix Method of Reservoir Design in Arid and Semi-arid Regions", In Proceeding of the Sahel Forum on the Stateof-the-art of Hydrology and Hydrogeology in the Arid and Semiarid Area of Africa. M. Demissie and E Stout (Eds) 129-136 IWRA Urbana Illions, USA

.Ragab, R. Austin, B. and Moidinis. (2001) "Reservoir Storage Capacity and Probability of Failure Model" Hydrology Earth System Sciences (54), 563-568

Raheem, E. and Khan, S.H. (2002) "Combining Probability of Emptiness and Mean First OverflowTime of a Dam to Determine Its Capacity", Journal of Spatial Hydrology. Vol.2 No.2 
TAHAL Consultant Engineering Ltd (1992) "Feasibility Study for Kano River Irrigation Project (Phase I ) Extension Vl. I \& II" 52,Rehor Ibn Gvirol Tel-Aviv, Israel Tel 436434

Wilson, E.M. (1990) Hydrology for Engineers Forth Edition Macmillan Press Ltd. London.

Woo Ming-ko and Tarhule, A. (1994) "Streamflow Drought of Northern Nigeria Rivers, Department of Geography", McMaster University Hamilton, Ontand Canada L85 4k1, Hydrological Sciences Journal. 39.1

WRECA (1974) Hydrologic Yearbook 1963-64, 1964-65, 1965-66, 1966-67, 1967-68, Water Resources Engineering Construction Agency Kano State, Nigeria WRECA(1989) Hydrologic Yearbook.

Figure 1: Distribution of average monthly water demand on Tiga Reservoir in million cubic metres.

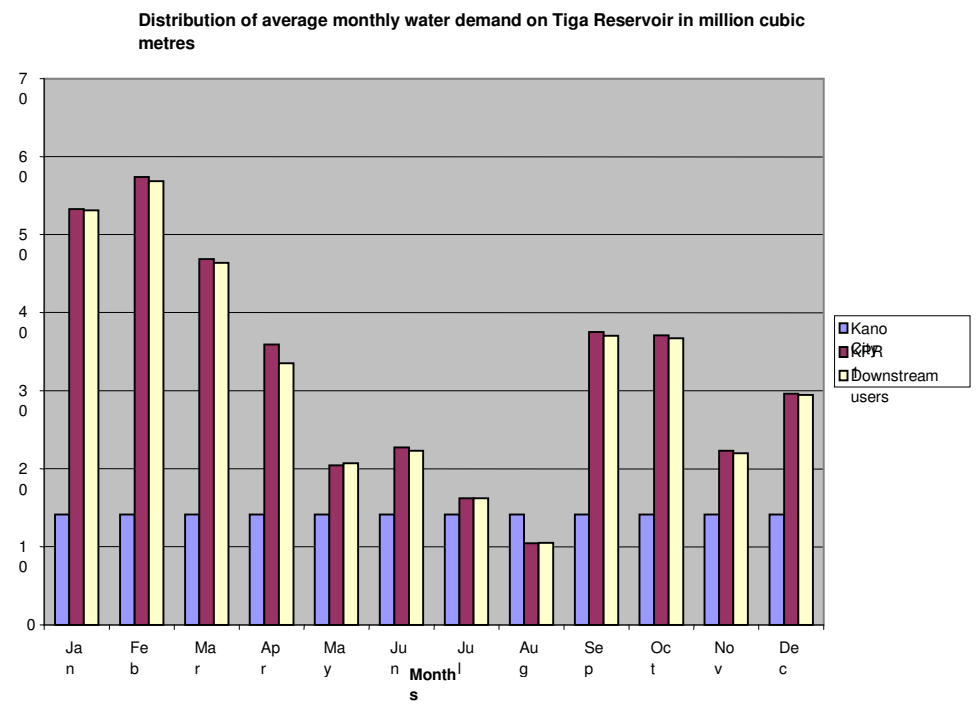


Fig 2: Monthly Probability of Faliure

Figure 3: Probability of failure of Tiga reservoir.

Probability of failure of Tiga Dam

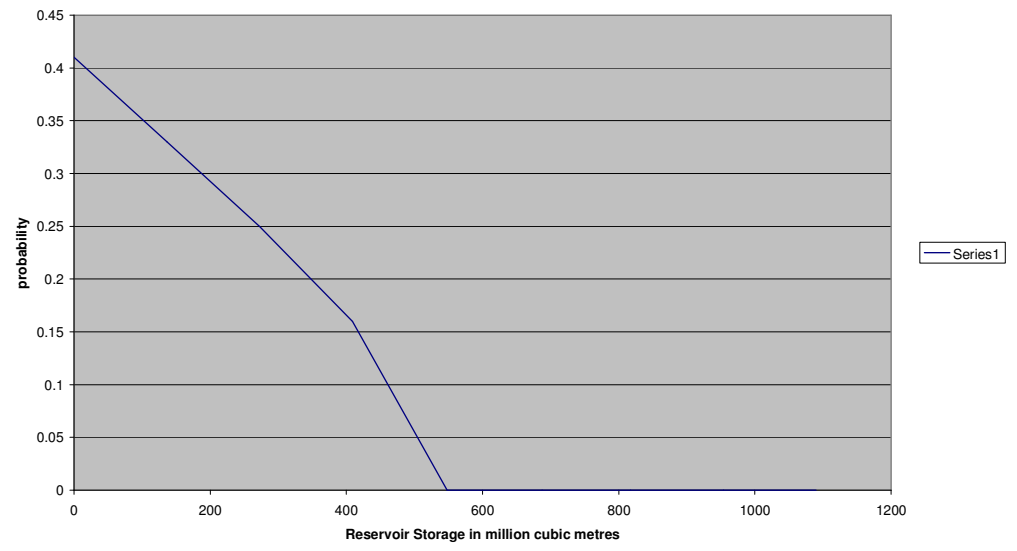


Table 1: Probability distribution for starting and finishing in any zone

Starting Zone Vt

\begin{tabular}{|c|c|c|c|c|c|c|c|c|c|c|}
\hline & & 0 & 1 & 2 & 3 & 4 & 5 & 6 & 7 & 8 \\
\hline & 0 & 0.0000 & 0.0000 & 0.0000 & 0.000 & 0.000 & 0.000 & 0.000 & 0.000 & 0.000 \\
\hline & 1 & 0.00595 & 0.00595 & 0.00595 & 0.00595 & 0.0000 & 0.000 & 0.0000 & 0.000 & 0.000 \\
\hline & 2 & 0.0000 & 0.0000 & 0.0000 & 0.0000 & 0.00595 & 0.00595 & 0.0000 & 0.0000 & 0.0000 \\
\hline & 3 & 0.00595 & 0.00595 & 0.00595 & 0.00595 & 0.0000 & 0.0000 & 0.00595 & 0.0000 & 0.0000 \\
\hline$\stackrel{F}{ \pm}$ & 4 & 0.0000 & 0.0000 & 0.0000 & 0.0000 & 0.00595 & 0.00595 & 0.0000 & 0.00595 & 0.0000 \\
\hline $\mathscr{Q}$ & 5 & 0.03572 & 0.03572 & 0.03572 & 0.01786 & 0.0000 & 0.0000 & 0.00595 & 0.0000 & 0.00595 \\
\hline N & 6 & 0.01191 & 0.01191 & 0.01191 & 0.02976 & 0.01191 & 0.02976 & 0.0000 & 0.00595 & 0.0000 \\
\hline.$\cong$ & 7 & 0.02381 & 0.02381 & 0.02381 & 0.01191 & 0.02976 & 0.02976 & 0.01191 & 0.0000 & 0.00595 \\
\hline 语 & 8 & 0.0000 & 0.0000 & 0.0000 & 0.01191 & 0.02976 & 0.02381 & 0.05952 & 0.07143 & 0.07143 \\
\hline
\end{tabular}

Table 2: Zonal distribution of capacity

\begin{tabular}{|l|l|l|l|l|l|l|l|l|l|}
\hline Zones & 0 & 1 & 2 & 3 & 4 & 5 & 6 & 7 & 8 \\
\hline Capacity & 0 & 136.25 & 272.5 & 408.75 & 548 & 681.25 & 817.5 & 953.78 & 1090 \\
\hline
\end{tabular}


Assessment of Reservoir Storage in Semi-Arid Environment Using...

Table 3: Steady state probability distribution for starting and finishing in any zone

\begin{tabular}{|l|l|l|l|l|l|l|l|l|l|}
\hline & 0 & 1 & 2 & 3 & 4 & 5 & 6 & 7 & 8 \\
\hline 0 & 0.000 & 0.000 & 0.000 & 0.000 & 0.000 & 0.000 & 0.000 & 0.000 & 0.000 \\
\hline 1 & 0.001 & 0.001 & 0.001 & 0.001 & 0.001 & 0.001 & 0.001 & 0.001 & 0.001 \\
\hline 2 & 0.005 & 0.005 & 0.005 & 0.005 & 0.005 & 0.005 & 0.005 & 0.005 & 0.005 \\
\hline 3 & 0.021 & 0.021 & 0.021 & 0.021 & 0.021 & 0.021 & 0.021 & 0.021 & 0.021 \\
\hline 4 & 0.011 & 0.011 & 0.011 & 0.011 & 0.011 & 0.011 & 0.011 & 0.011 & 0.011 \\
\hline 5 & 0.060 & 0.060 & 0.060 & 0.060 & 0.060 & 0.060 & 0.060 & 0.060 & 0.060 \\
\hline 6 & 0.021 & 0.021 & 0.021 & 0.021 & 0.021 & 0.021 & 0.021 & 0.021 & 0.021 \\
\hline 7 & 0.080 & 0.080 & 0.080 & 0.080 & 0.080 & 0.080 & 0.080 & 0.080 & 0.080 \\
\hline 8 & 0.700 & 0.700 & 0.700 & 0.700 & 0.700 & 0.700 & 0.700 & 0.700 & 0.700 \\
\hline
\end{tabular}

Table 4: Monthly probability distribution

\begin{tabular}{|l|l|l|l|l|l|l|l|l|l|l|l|l|}
\hline Month & Jan & Feb & Mar & APR & May & Jun & Jul & Aug & Sep & Oct & Nov & Dec \\
\hline Prob & 0.083 & 0.167 & 0.249 & 0.332 & 0.332 & 0.00 & 0.00 & 0.00 & 0.00 & 0.00 & 0.00 & 0.00 \\
\hline
\end{tabular}

